\title{
Andrés Lamas y la reconfiguración de las tareas policiales: reforma, administración interior y gobierno de las ciudades. Montevideo, 1843-1844
}

Andrés Lamas and the reconfiguration of police: reform, administration and city government. Montevideo, 1843-1844

Andrés Lamas et la reconfiguration des tâches de la police : réforme, administration interne et administration municipale. Montevideo, 1843-1844

\section{Nicolás Duffau}

\section{OpenEdition}

Journals

Edición electrónica

URL: http://journals.openedition.org/rhj/3771

DOI: 10.4000/rhj.3771

ISSN: 0719-4153

Editor

ACTO Editores Ltda

\section{Referencia electrónica}

Nicolás Duffau, «Andrés Lamas y la reconfiguración de las tareas policiales: reforma, administración interior y gobierno de las ciudades. Montevideo, 1843-1844 », Revista Historia y Justicia [En línea], 14 I 2020, Publicado el 27 julio 2020, consultado el 27 julio 2020. URL : http://journals.openedition.org/ rhj/3771 ; DOI : https://doi.org/10.4000/rhj.3771

Este documento fue generado automáticamente el 27 julio 2020.

Revista Historia y Justicia 


\section{Andrés Lamas y la reconfiguración de las tareas policiales: reforma, administración interior y gobierno de las ciudades. Montevideo, 1843-1844}

Andrés Lamas and the reconfiguration of police: reform, administration and city government. Montevideo, 1843-1844

Andrés Lamas et la reconfiguration des tâches de la police : réforme, administration interne et administration municipale. Montevideo, 1843-1844

Nicolás Duffau

\section{NOTA DEL EDITOR}

Recibido : 03 de marzo de 2020 / Aceptado : 10 de junio de 2018

\section{Introducción}

1 Este trabajo toma como referencia la actuación de Andrés Lamas (1817-1891) como jefe político y de policía de Montevideo durante los dos primeros años del Sitio Grande (1843-1844), que marcó el inicio del asedio a la ciudad de Montevideo durante la llamada "Guerra Grande" (1838-1852), enfrentamiento político y militar que marcó la década de 1840 en todo el territorio rioplatense. El sitio de Montevideo comenzó el 16 de febrero de 1843, fecha en la que el Ejército Unido de Vanguardia de la Confederación Argentina, comandado por el General Manuel Oribe, puso sitio a la ciudad-puerto de Montevideo. A partir de febrero de 1843, y hasta octubre de 1851, en el Estado Oriental 
del Uruguay convivieron dos gobiernos: uno limitado a Montevideo y su línea defensiva, comúnmente llamado de la Defensa, y el otro, conocido como del Cerrito por la zona en que se ubicó-, que en el correr de la década de 1840 controló los extramuros de la ciudad y la mayor parte del territorio.

2 En ese contexto, Andrés Lamas fue designado jefe político y de policía, una función medular para la seguridad interna de la plaza de Montevideo. Las biografías sobre Lamas destacan su carácter de historiador, de coleccionista, de bibliófilo, de periodista, y su actuación pública siempre es analizada en relación con su función como diplomático desde 1847 en adelante ${ }^{1}$. Sin embargo, Lamas ocupó distintos cargos públicos desde la primera mitad de la década de 1830: con 17 años acompañó, como funcionario del Ministerio de Gobierno, a su padre Luis Lamas, cuando éste se desempeñó como jefe político y de policía de Montevideo (1831-1835). En 1842 Andrés Lamas fue nombrado juez letrado del Crimen y al año siguiente jefe político y de policía donde estuvo hasta mayo de 1844. Luego de la jefatura política llegó al Ministerio de Hacienda y finalmente, el 9 de noviembre de 1847, fue designado "Enviado Extraordinario y Ministro Plenipotenciario" ante la corte de Rio de Janeiro, desde donde negoció con el Imperio del Brasil el tratado defensivo contra Rosas, así como los acuerdos sobre límites de 1851 .

3 Lamas cuenta con una profusa bibliografía ${ }^{2}$ sobre las temáticas más variadas, pese a lo cual en sus libros no sistematizó sus escritos policiales, mayoritariamente disposiciones administrativas, pero también correspondencia privada en la que daba cuenta de su visión acerca de las reformas de la policía y las propuestas para modificar algunas tareas. El único texto de carácter policial de autoría de Lamas y seleccionado en sus escritos es el Nomenclátor, que veremos más adelante ${ }^{3}$. Los Apuntes Estadísticos, otro texto policial de Lamas, fue publicado en forma fragmentaria en $1851 \mathrm{y}$ en su totalidad en 1928 por Horacio Arredondo (hijo), quien insistió en su importancia como documento demográfico, pese a que en la introducción hay distintas consideraciones sobre administración.

4 Analizado con perspectiva histórica, el trabajo de Lamas resulta fundamental, pues durante el año y medio que duró su jefatura, inició un proceso de reforma de la institución policial, cuyos efectos contribuyeron a modificar las tareas policiales en forma posterior. Varios de los instrumentos de control urbano utilizados por Lamas (como pasaportes o papeletas de conchabo) ya existían en forma previa al período considerado, pero lo que marcó el bienio 1843-1844 fue el impulso a las reformas administrativas y el uso de diversos recursos que buscaban mejorar la actuación policial ${ }^{4}$. Intentaremos mostrar de qué forma este período excepcional en el cual la jurisdicción de Montevideo quedó cercada por un asedio, permitió hacer de la ciudad una especie de laboratorio para aumentar el poder del naciente Estado.

5 Lamas consideró a la policía como una "consecución lógica de la Administración" y se refería a las funciones policiales como parte de una "ciencia"5. La descripción de algunas de las tareas propuestas o emprendidas durante la administración Lamas dan cuenta del ideal existente sobre cuáles eran las funciones que debía cumplir el Estado en un creciente proceso de racionalidad burocrática que apuntaba a formar instituciones capaces de controlar todo el territorio (aunque un intento tan ambicioso no fuera posible a lo largo de todo el siglo XIX). Podemos sostener, como hipótesis central del trabajo, que Lamas fue uno de los primeros reformadores de la policía montevideana, por medio de un proceso en el que buscó, por un lado, organizar la 
ciudad y, por otro, dotar a sus subalternos de algunos instrumentos "modernos" que facilitaran el cumplimiento de sus tareas.

6 En el artículo analizaremos un conjunto de fuentes históricas primarias entre las que se destacan la documentación oficial de la Policía de Montevideo, del Ministerio de Gobierno y el epistolario de Andrés Lamas, así como algunos de sus escritos. El artículo sigue algunos de los principales tópicos que marcaron las propuestas de reforma, que permiten encontrar un nuevo foco de observación sobre el proceso de construcción estatal. El trabajo se inserta en una bibliografía cada vez más robusta sobre trayectorias policiales, que, a partir de estudios de caso, intenta estudiar distintas configuraciones e itinerarios administrativos. En este trabajo nos concentraremos en las tareas de carácter administrativo, sin desconocer el rol político de los jefes de policía ${ }^{6}$. Esa relación poder político-poder policial debe ser problematizada en forma permanente $y$, a su vez, descartar las visiones que presentan a la policía como un aparato con lógicas de funcionamiento unívocas que se resumen en el combate al delito ${ }^{7}$. Por el contrario, en este período encontramos una policía preocupada por el problema del orden interior de la ciudad, cumpliendo tareas de lo que en el período se consideraba "baja policía", es decir una "técnica de gobierno" caracterizada por la intervención en el espacio público para saber datos básicos de la población, organizar el suministro de distintos bienes de consumo, la circulación de mercancías, la regulación del mercado laboral y las tareas de tipo sanitario ${ }^{8}$. En su estudio sobre el "orden público", el historiador francés François Godicheau señala que el $60 \%$ de las disposiciones contenidas en los manuales de policía europeos estaban asociadas a tareas completamente ajenas a la represión del delito y el crimen". La idea de "orden público", sostiene el mismo autor, "es entonces, primero, el orden de lo público", que explicaría el pasaje de sociedades jerarquizadas y controlables a plantas urbanas en crecimiento, extensivas, en algún sentido igualitarias y a sociedades carentes de una autoridad vertebradora del poder. Esa idea de orden, asociada a la paz interior, expresó la visión de los grupos políticos y económicos dominantes ${ }^{10}$.

\section{Andrés Lamas, jefe político y de policía de Montevideo}

7 Las jefaturas políticas y de policía, existentes desde 1829, buscaban la centralización del poder político y policial en un mismo sistema unitario para todos los departamentos que en ese entonces conformaban el Uruguay ${ }^{11}$. Como señala Ana Frega, este tipo de resoluciones fueron una manifestación partidaria del centralismo o sistema de unidad que formaba parte de las discusiones políticas del constitucionalismo hispanoamericano, pero que a su vez chocó con los regionalismos que debilitaron esa pretensión centralizadora ${ }^{12}$. Las jefaturas se consagraron en la Constitución de 1830, en su artículo 118 que estableció que "en el pueblo cabeza de cada Departamento" se encargaría a "un agente del Poder Ejecutivo", que llevaría "el título de Jefe Político, y al que corresponderá todo lo gubernativo de él; y en los demás pueblos subalternos" ${ }^{13}$. En el caso de Montevideo, el jefe político y de policía estaba acompañado por dos oficiales auxiliares, comisarios por cada sección (siete en el período), 30 cabos celadores y 170 celadores, aunque, por lo general, no se llegaba a completar todas las vacantes existentes; a su vez eran auxiliados por los tenientes alcaldes de las manzanas que dividían la ciudad. 
8 La jefatura política y de policía debía complementar sus actividades con las de la Junta Económica Administrativa, también presentes en la Constitución de 1830 y encargada de la administración de la ciudad. En los hechos, las juntas tenían una actuación casi nula y sus tareas fueron monopolizadas por la policía hasta, al menos, la década de 1850, período en el cual se comenzó a vislumbrar una mayor preocupación porque cada institución cumpliera con las tareas delimitadas en la legislación ${ }^{14}$. Lamas asumió la jefatura en un contexto político adverso, marcado por la derrota militar de las fuerzas montevideanas el 6 de diciembre de 1842, que precipitó el sitio de Montevideo en febrero de 1843. Desde esa fecha y hasta mayo del año siguiente, Lamas ocupó el cargo de jefe político y de policía y llevó adelante distintas estrategias que buscaron reafirmar el rol que cumplía la policía dentro de la ciudad: mantenimiento del orden, control de poblaciones, organización de la defensa interior. En distintas notas cursadas al ministro de Gobierno o a las comandancias militares de las fuerzas apostadas en Montevideo, Lamas insistió en que era la policía y no otra autoridad la que debía gobernar la ciudad. En marzo de 1843 solicitó al gobierno que "sin pérdida de momento" estableciera en forma "clara" cuáles "son las funciones de la Policía, a quien obedecen las fuerzas que esta tiene para llenar las que hasta ahora considera como suyas". Si bien esa nota genera cierta sensación de desconcierto, Lamas planteó que debía existir un mando unificado y afirmó que sólo cumpliría órdenes del Ministerio de Gobierno ${ }^{15}$.

\section{Vigilar y conocer Montevideo}

Un problema generado por el sitio fue la presencia fluctuante de población que llegó a Montevideo. Según estimaciones, unas tres mil personas provenientes del medio rural arribaron a la ciudad en forma previa al asedio ${ }^{16}$. A eso se agregó un "aumento de la población menesterosa y enferma" ${ }^{17}$, que probablemente comprendiera a todas aquellas personas incapacitadas para hacer la guerra y la importante corriente migratoria europea que desde la década de 1830 provocó un significativo aumento de la población. En 1843, de los 31189 habitantes censados, sólo 11.431 eran "orientales". Los seguían 5 324 franceses, 4205 italianos, 3406 españoles, 2553 "argentinos", 1344 africanos, 659 portugueses, 606 ingleses, 492 brasileños y 1169 de diversas nacionalidades ${ }^{18}$.

La policía se convirtió en uno de los principales recintos de información sobre los flujos poblacionales, la situación habitacional, así como las diferentes actividades comerciales. La necesidad de contar con datos precisos valía tanto para los habitantes ya asentados en la ciudad, como para aquellas personas recién llegadas y entre las cuales se sospechaba que podían encontrarse enemigos políticos, capaces de hacer la guerra desde el interior de la ciudad, recopilando información, generando rumores, noticias o directamente saboteando la actuación gubernamental ${ }^{19}$. El $1^{10}$ de marzo de 1843 un decreto firmado por Lamas expresó: "el enemigo mantiene culpables intelijencias con individuos de esta plaza, por medio de las familias de los traidores Orientales que tiene a su sueldo", los cuales "no han dejado de ser agentes de conspiración desde que el enemigo apareció delante de esta ciudad" ${ }^{20}$. El mismo decreto ordenó la expulsión de "las familias que residen en Montevideo de los individuos que hacen parte del ejército invasor" y de "las familias de los declarados prófugos y traidores por los edictos de Policía" ${ }^{21}$.

11 Otro tipo de población en movimiento eran los trabajadores zafrales sobre los cuales se buscó imponer algún tipo de reglamentación. La estructura ocupacional de Montevideo 
era característica de un núcleo urbano, portuario y mercantil. Según datos elaborados por Raquel Pollero, la mitad de la población masculina de Montevideo se dedicaba a la producción o el transporte ${ }^{22}$. Un proyecto de edicto fue promovido por Lamas en septiembre de 1843. Detrás de la propuesta se encontraba una vez más la noción de orden, puesto que lo que se buscaba con la disposición era reorganizar el espacio urbano y en concreto el mercado laboral, para lo que era imprescindible "distinguir en la sociedad el hombre laborioso y útil del vago y perjudicial". El edicto intentaba "marcar" a aquellas personas que se ocupaban de actividades laborales, de quienes la autoridad policial consideraba vagos, y, por ende, delincuentes. Serían considerados vagos y enviados a la justicia ordinaria todas las personas que fuesen detenidas por la policía y carecieran de "la correspondiente papeleta de matriculación" ${ }^{23}$. Incluso podían llegar a recibir una sanción judicial las personas que habían salido de fiadores de trabajadores que luego cometieron algún delito o falta de conducta. Si bien las penas correspondientes no se explicitan para ningún caso -porque eso quedaba a criterio del Juez Letrado-, la intervención judicial probablemente era pensada como un mecanismo de control, ya que no sólo quedaban involucradas las personas carentes de papeleta, sino sus posibles fiadores y hasta el empleador. En el fondo se trataba de una especie de red disciplinar. La vagancia y la falta de vigilancia llevaron a que las autoridades policiales mostraran una creciente preocupación por los sectores populares y por aquellas prácticas que alteraran el concepto de orden interior. El orden social y urbano, y la buena administración de la ciudad, dependían de la policía; la vigilancia sobre el mercado laboral, la transmisión de una noción de disciplina también se encontraba en línea con esos postulados. Lamas reafirmó esta noción durante su administración.

Confinar a los trabajadores a determinadas tareas, garantizaba la estabilidad que permitiera concretar las distintas actividades productivas y comerciales que se desarrollaban dentro de la ciudad. La disposición buscó "planificar una relación de dependencia que evite los trastornos a que está expuesta nuestra industria naciente" ${ }^{24}$. De este modo se estableció un registro de trabajadores matriculados que obligaba a todos los empleados a portar una papeleta que explicitara la "clase de trabajo" o "profesión", nombre del empleador, forma en que "le es pagado su salario", así como "domicilio y el de su principal [empleador]". La normativa comprendía a

"Todos los peones de albañil, de barraca, de saladero, de hornos, panadería, los que se ocupan en la estiba de buques, los lancheros y en general todos aquellos cuyos trabajos se paguen por día [...], los oficiales de carpintero, herrero, hojalatero, pintor, platero, zapatero y en general de todo asta mecánico cuyos trabajos se paguen por obra [...], los mozos de fonda, café, taberna, los cocineros, carreros y carretilleros, los dependientes de casas de comercio por menor, peones de quinta y chacra, y en suma todo aquel cuyo salario le sea pago por mes o por año".

En los casos en que la persona no contara con domicilio fijo, debía presentar a dos testigos fiadores, "vecinos respetables", que garantizaran que el portador de la papeleta era una persona de confianza. La normativa reguló los espacios y horarios laborales, en especial para la venta ambulante que quedó restringida a los menores de dieciséis años. De este modo, cada grupo social sufría un proceso de delimitación del territorio que podía habitar u ocupar, en un creciente proceso de formación del mercado laboral ${ }^{25}$. En la Ciudad Vieja, había zonas de trabajadores que debían ser controladas más allá del tipo de tarea que realizaban sus habitantes. Confinar a los hombres y mujeres que desarrollaban determinada actividad laboral a un espacio cerrado, era una forma de mantener el control urbano. Quienes cumplían actividades laborales en la pesca o la 
zona portuaria no podían desarrollar su actividad en otra zona de la ciudad que no fuera la que establecía el reglamento ${ }^{26}$. Esto permitía controlar el mercado laboral, pero también el espacio urbano. A su vez, cumplía una función policial en la medida que buscaba evitar todo desborde popular y, en la concepción de los grupos dirigentes, la presencia de contingentes de trabajadores sin control por las calles podía derivar en tumultos o asonadas.

A su vez, el texto se dedicaba a definir y sancionar la vagancia. Eran "vagos" todas las personas que carecían de un oficio o trabajo conocido. Situación harto difícil de determinar: al menos desde mayo de 1842 , la ciudad había recibido un importante contingente de población procedente del medio rural, dentro del cual había personas sin oficio o tareas conocidas. Podríamos pensar que el edicto apuntaba a generar mecanismos de control social ante el aumento de población, ya que obligaba a que todos los que pudieran ser laboralmente activos se conchabaran en alguna tarea. Para eso era importante contar con relaciones sociales que facilitaran la contratación o recomendación, de lo contrario otra posibilidad era formar parte de los batallones de línea o cumplir tareas militares.

15 A este último aspecto se agrega un elemento más: el proceso de abolición de la esclavitud, el 12 de diciembre de 1842. Por esta disposición los afrodescendientes ya no serían esclavos, pero debían ser destinados al servicio de las armas. De este modo la población afro, ya de por sí vigilada por la policía, ahora contaba con la libertad que le permitía transitar por la ciudad sin autorización de amos o empleadores. Por ende, sobre la policía recayó la tarea de controlar e incluso confinar a actividades laborales a esta población que ya no dependía de los mandatos de sus amos ${ }^{27}$.

Entrar o salir de la ciudad implicaba presentarse ante la autoridad policial para mostrar el pasaporte y dar una ubicación precisa del lugar de asentamiento o la dirección de destino en caso de abandonar Montevideo. Una nota de Lamas, fechada el 17 de marzo de 1843, sentó las bases del funcionamiento de ingreso/egreso y prohibió admitir en las casas particulares o de inquilinato a "individuos recién llegados" sin que antes se presentaran ante la policía. Los comisarios y los tenientes alcaldes de cada sección y manzana debían conocer a todos los habitantes de su jurisdicción y llevar un registro pormenorizado. Si una persona no alertaba a la autoridad sobre un huésped, así fuera familiar, podía recibir una sanción que iba desde penas "pecuniarias" de "veinte y cinco hasta cien pesos", "de prisión con destino a trabajos públicos desde ocho días hasta un mes

“[...] sin perjuicio de sujetar a los que incurran en ellas a un tratamiento más severo en los hechos que descubran malicia e induzcan sospechas vehementes, como si el ciudadano no presentado hubiera venido de territorio enemigo o fuera conocido por simpatías o antecedentes que lo liguen a esa horda de infames que hacen mina la prosperidad de su país para llenar el envidioso encono del extranjero"28.

La situación de fragilidad del gobierno montevideano llevó a que el jefe político se preocupara por saber quiénes habitaban la ciudad con una intención claramente política, pero también administrativa. Para ello propuso un sistema de vigilancia política a través de integrantes del cuerpo policial (que finalmente no se habría concretado, aunque fue denunciado por la prensa opositora $\left.{ }^{29}\right)$ y también otras formas de vigilancia de carácter informal, mediante redes de informantes no pertenecientes a los cuadros policiales que enviaban hacia la jefatura, a través de un comisario o en 
forma directa, datos sobre posibles enemigos. Buena parte de esa papelería se conserva en la correspondencia personal de Lamas.

Las denuncias no eran sólo por motivos políticos, sino también por acopiar mercaderías o esconder armas. Algunas de esas notas tienen firma, otras son anónimas y en algunos casos se recurre al seudónimo. Por ejemplo, "Un Padre de familia" denunció al propietario del "almacén de menudeo" de la calle Rincón $n^{\circ} 76$, pues adulteraba los pesos hasta en diferencias "de trece por ciento en la cantidad que de buena fe se le ha pedido y satisfecho" y solicitó "castigar un escándalo tan perjudicial para toda la población y que tan poco honor le hace a la misma policía" ${ }^{30}$. Si bien resulta difícil determinar cuán espontáneas eran esas delaciones, lo interesante del punto es pensar cómo la policía fue aumentando su autoridad para que las personas decidieran delatar a sus vecinos o depositaran en un agente policial, y en última instancia en el jefe político, las expectativas de que se hiciera justicia.

Vinculado a las denuncias por acopio o adulteración en el peso de los bienes de consumo, el jefe político impulsó, en marzo de 1843, la formación de una Comisión de Subsistencias, que además presidió, encargada de "indagar la cantidad de víveres existentes", que permitiera elaborar una "prudente previsión del tiempo que podría subsistir la plaza sujeta al parcial asedio en que la sostiene el tirano de Buenos Aires". La comisión debía actuar en coordinación con los comerciantes que serían supervisados por la policía, para conocer el detalle de los bienes de consumo que "falten o se hallen en menor cantidad". Por eso, los oficiales de policía recorrían la ciudad con una planilla que contaba con un largo listado de productos, para saber dónde faltaba, dónde sobraba y a qué precio se vendía. La planilla, además del listado de productos, recuperaba el nombre del comerciante, la calle y el número de casa, por lo que permitía acceder a información relevante sobre quién ocupaba cada inmueble o comercio ${ }^{31}$. Los comisarios de sección se encargaron de perseguir todos los excesos cometidos por los comerciantes que adulteraban pesas, vendían productos de mala calidad o se excedían del precio fijado por el gobierno, aunque también el propio Lamas señaló que la tasa "a los artículos de consumo" podía ser vista como una limitante del "interés individual" de los comerciantes que tratarían de conseguir productos si los podían vender ${ }^{32}$. No obstante, pese a esa defensa del liberalismo económico, la autoridad continuó regulando precios y la circulación de mercaderías.

Otra esfera de intervención fue el mercado de los bienes inmuebles. El trasiego de población y la huida de Montevideo de varios de los llamados "enemigos" motivaron la creación de una comisión de bienes de prófugos, que evitaría las apropiaciones indebidas, otro de los problemas que surgió con el abandono de bienes de distinto tipo e inmuebles ${ }^{33}$. Esos bienes, muchos de los cuales estaban en manos de particulares que se aprovecharon de la situación de conflicto y el clima al interior de Montevideo, pasaron a manos de la jefatura de policía. La autoridad recuperaba recursos preciados en un contexto de economía de guerra, pero al mismo tiempo se convertía en un garante de la propiedad privada, ya que, aunque se tratara de bienes de enemigos, era imprescindible evitar malos ejemplos de indisciplina, robo o apropiación indebida.

21 En todas las disposiciones lo que se buscaba era acumular conocimientos sobre la planta urbana. En la visión de Lamas, la policía no era solo una institución reguladora, sino que de ella dependía la formación de datos centrales para organizar la ciudad. Un proyecto en esa dirección podría ser la creación del Instituto Histórico y Geográfico (IHG). Si bien la formación de una institución de este tipo podría carecer de una 
relación directa con las tareas policiales, en la concepción de Lamas, estaba vinculada al desarrollo urbano. La justificación de fundación, enviada por Lamas al ministro de Gobierno el 23 de mayo de 1843, sostuvo que el Instituto buscaba promover los "estudios" sobre las "condiciones geográficas de nuestro país", organizar la "estadística sin cuyo pleno conocimiento es imposible establecer sobre bases sólidas ningún sistema de administración y rentas" y "formar un depósito de manuscritos, libros, mapas pertenecientes a la historia antigua y moderna de estas regiones". Buscaba ser un espacio de reunión de "todos los hombres de letras que tenga el país, [...] llamados a despojarse, en las puertas del Instituto, de sus prevenciones y colores políticos, [para] entrar a él a ocuparse tranquilamente en objetos de interés común y permanente" ${ }^{34}$.

Lamas pensó la ciudad como un espacio de irradiación de la cultura y la acumulación de conocimiento que complementaba la tarea policial era una forma de hacer de las funciones policiales parte de esa ciencia de la administración a la que se refería. La policía ya no actuaría sólo mediante una postura de reacción ante hechos consumados, sino que tenía que escrutar la ciudad en todos sus rincones, conocer quiénes eran sus habitantes, dónde se alojaban, a qué se dedicaban y eventualmente saber de sus prácticas y conductas. Esa posibilidad excedía el contexto de guerra, aunque, sin duda, estaba influida por la situación. Al mismo tiempo, del gobierno de la ciudad dependía el embellecimiento de la planta urbana, el fomento de las actividades culturales y el conocimiento sobre el pasado. Esta conjunción de tareas, que se resumen en los escritos de Lamas, encontró un punto de contacto en las propuestas para modificar la nomenclatura de las calles y plazas de la ciudad y, al mismo tiempo, conocer los límites geográficos y las principales cifras demográficas y productivas de la vida en Montevideo.

\section{Calles, mapas y números: instrumentos para organizar la ciudad}

Montevideo se manifestaba como una ciudad en crecimiento, era el centro administrativo, económico, comercial y social del Estado Oriental. Desde comienzos de la década de 1830 las autoridades de la ciudad discutían sobre los límites y la jurisdicción, al tiempo que se sucedían distintos proyectos para ampliar la planta urbana. El Departamento de Montevideo fue creado el 27 de enero de 1816, pero sus límites jurisdiccionales definitivos se fijaron el 28 de agosto de $1835^{35}$. El problema no era legal, sino más vinculado al uso que parte de la población daba al territorio, lo que generaba que no existiera precisión sobre dónde empezaba o terminaba la jurisdicción.

En 1829 el gobierno ordenó el inicio de la demolición de las murallas de la fortificación colonial que delimitaba a la Ciudad Vieja; la nueva zona de la ciudad, también llamada Nueva se extendió desde el límite de la Ciudad Vieja hasta el ejido, a aproximadamente un kilómetro al Este del casco fundacional. Sin embargo, la demolición completa de los muros coloniales y la unión entre la nueva y la vieja ciudad se concretó luego de la Guerra Grande. Desde la década de 1830 los sucesivos conflictos políticos y militares -y, a partir de 1843, el sitio- retrasaron las obras y contribuyeron a generar esa situación de indeterminación sobre límites y jurisdicciones. Esto dificultaba el trabajo policial, ya que comisarios $u$ oficiales no siempre tenían claridad sobre la jurisdicción que les correspondía vigilar y controlar 


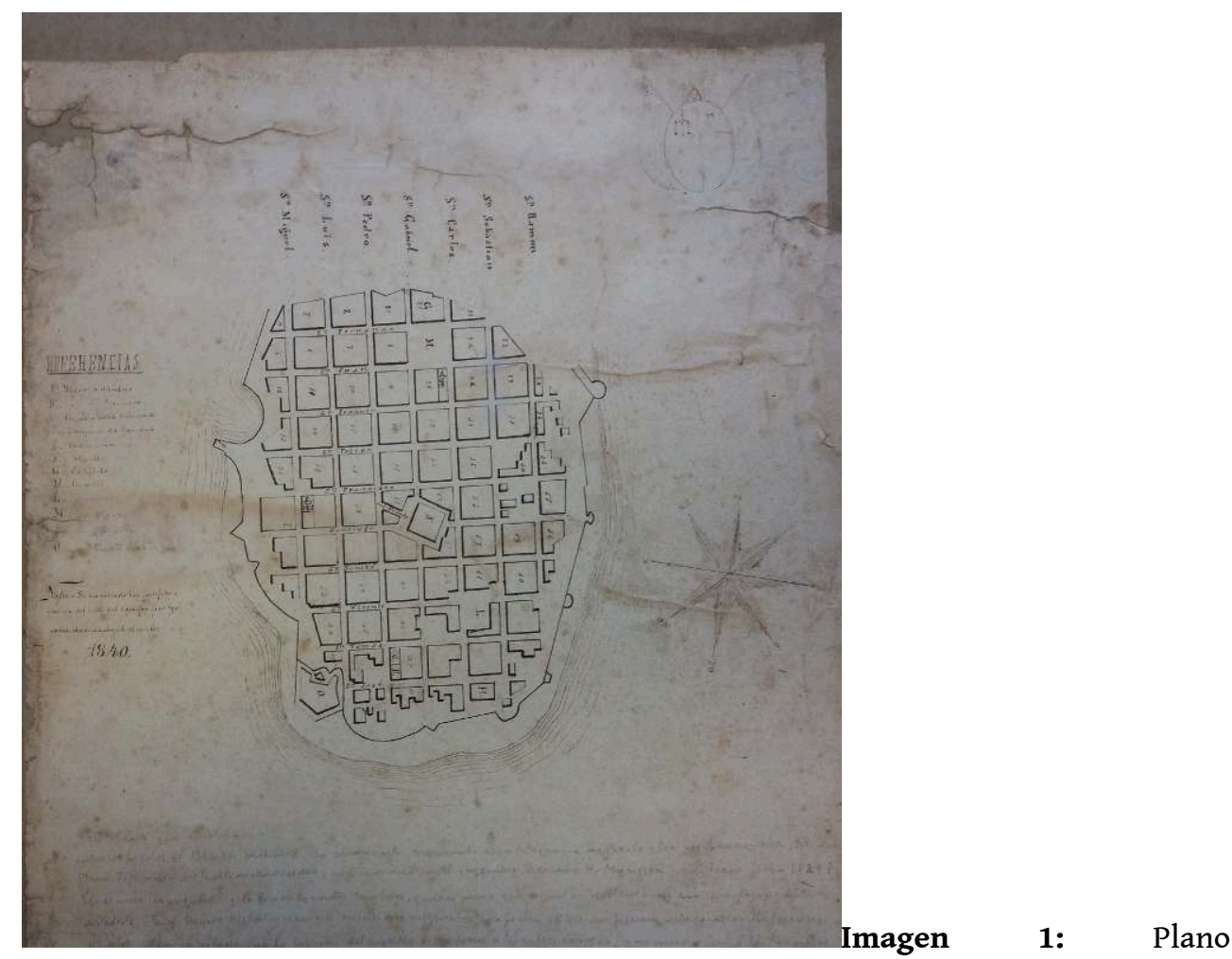

topográfico del pueblo de Montevideo, 1829. Reproducción de Bacle y Cía., dibujado por Adrián Henrique Mynssen. Museo Histórico Nacional [Uruguay], Colección Cartográfica.

Lamas, plenamente consciente de esa situación, se preocupó por dotar a la actuación policial de un nuevo nomenclátor y de un mapa topográfico moderno que facilitara la tarea. A este aspecto se agrega otro elemento ya señalado: el crecimiento demográfico de Montevideo, que forzó a que la policía precisara tener un conocimiento cada vez más asentado sobre los habitantes de la ciudad. Para ello, un aliado insustituible era la estadística, que también fue utilizada por el jefe de policía.

Si bien Montevideo estaba sitiada, el gobierno de la ciudad comprendía la llamada Ciudad Vieja y la ciudad nueva o extramuros, donde se encontraban las localidades de la Aguada, Arroyo Seco, Miguelete, Cordón y Tres Cruces, zonas en las que terminaba la línea defensiva. Como ejemplo del crecimiento demográfico y urbano, en 1836 Montevideo había abandonado la división en tres secciones policiales (primera, segunda de extramuros que abarcaba Cordón y Aguada, y tercera que comprendía Maroñas y el Pantanoso), aumentándolas a siete, cada una a cargo de un comisario ${ }^{36}$. Las tres primeras secciones comprendían a la Ciudad Vieja, mientras las restantes cuatro se dividieron en cuarta (el Cordón), quinta (la Aguada), sexta (Maroñas) y séptima (Pantanoso). A esta delimitación en secciones se agregaban otras zonas de la ciudad como Punta Brava, el Cerro o la Aldea. Lamas reafirmó la relevancia de los comisarios de sección, cuyas funciones hasta entonces no estaban completamente claras o habían sido cuestionadas con insistencia, contrariamente a lo que ocurrió en otras ciudades de la región ${ }^{37}$. Lamas reafirmó a los comisarios como jerarquías centrales en el esquema de funcionamiento policial y realizó propuestas para que Montevideo contara con un nuevo nomenclátor que facilitara la ubicación de las calles y un plano aggiornado de la ciudad.

27 Lamas presentó su proyecto de nomenclátor y numeración de puertas el 21 de mayo de 1843, y el 22 de mayo el gobierno aprobó la iniciativa ${ }^{38}$. Este impulso a un nuevo 
nomenclátor no era el primero del siglo XIX, ya que en otras ocasiones se habían presentado propuestas que finalmente se frustraron ${ }^{39}$. El nomenclátor de Lamas ha sido analizado en su dimensión historiográfica (como construcción republicana en el período de lucha por la independencia ${ }^{40}$ ), pero no en función de su relevancia como instrumento policial. En la fundamentación, Lamas señaló el contenido histórico de la iniciativa, que buscaba "rendir homenaje a las glorias nacionales que están ya fuera del dominio de la discusión y son objeto de respeto y amor para todos los hijos de esta tierra", "hombres públicos que han trabajado y convalidado la independencia y la libertad de la doctrina sin desertar su bandera, en los duros trances y tribulaciones con que la Providencia ha querido poner a prueba la pureza y la verdad de sus ejercicios y de sus sacrificios". Sin duda el nuevo nomenclátor respondió a la intención de modificar las denominaciones coloniales, pero también puede ser analizado como un elemento que contribuyó a conformar un nuevo mapa de saberes policiales, que permitía una localización exacta de los espacios y de las casas. La numeración de domicilios y comercios y la correcta referenciación buscaba eliminar las expresiones de uso corriente con la que se identificaba a las viviendas o los lugares. De acuerdo con el jefe político, el nomenclátor y la nueva numeración de puertas eran dos medidas imprescindibles para una ciudad en expansión que precisaba "orden y gobierno"; tenía una finalidad económica, ya que permitiría conocer en detalle todas las construcciones existentes, fundamental para "la buena recaudación de varios impuestos"; y, por último, redundaría en un beneficio del comercio "y el decoro mismo de esta población" ${ }^{41}$.

Contar con una señalética moderna y numeración en las viviendas o comercios, contribuyó en forma decisiva con otras tareas policiales como el plano topográfico de 1843, el catastro de la ciudad y el censo efectuado ese mismo año. A su vez facilitó la tarea de vigilancia del espacio público y el privado mediante el relevamiento que llevaban adelante los comisarios y tenientes alcaldes, que debían conocer sus zonas al detalle ${ }^{42}$. Lamas confirió mucha importancia a los planos y mapas de Montevideo, que debían ser elaborados siguiendo las técnicas topográficas modernas.

En 1843 pidió a la Comisión Topográfica la elaboración de un plano "de la Antigua y Nueva Ciudad de Montevideo con arreglo a la nomenclatura de las calles propuestas". El plano de Juan Manuel Besnes e Irigoyen -oficial y litógrafo de la Comisión- fue el primero de un total de ocho (editados en Londres y París) que se sucedieron durante el sitio y que tomaron la delimitación de 1843 como referencia ${ }^{43}$. 


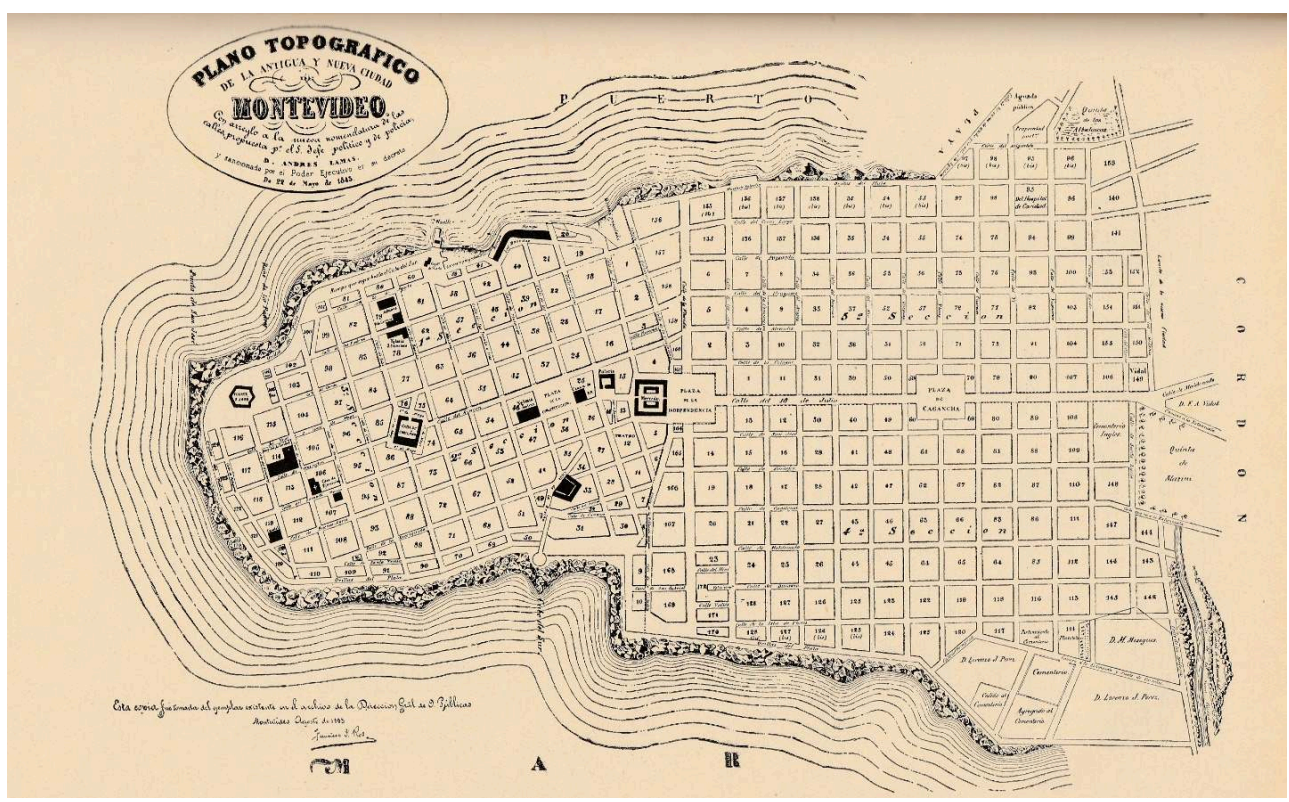

Imagen 2: Plano topográfico levantado por Juan Manuel Besnes e Irigoyen a pedido de Andrés Lamas, 1843. Tomado de Beretta, Ernesto, Imágenes para todos. La producción litográfica, la difusión de la estampa y sus vertientes temáticas en Montevideo durante el siglo XIX. Primera etapa, de la constitución del Estado Oriental al fin de la Guerra Grande (1829-1851), Montevideo, CSIC-UdelaR, 2015, p. 178.

El plano diseñado por Besnes e Irigoyen seguía la propuesta elaborada por el ingeniero José María Reyes, encargado desde 1829 de la demolición de las murallas coloniales y presidente de la Comisión Topográfica desde 1831, quien había realizado una propuesta de planificación que unía la Ciudad Vieja con la Nueva. En la iniciativa, Montevideo era dividido en 136 manzanas de cien varas de lado, que llevaba a la ciudad prácticamente al doble de su tamaño ${ }^{44}$. Fernando Aliata advirtió que en el Río de la Plata estas modificaciones se vinculaban a los intentos por conformar una "ciudad regular", ordenada en cuadrículas y que intentó reasignar un nuevo valor a los espacios públicos, construir edificios para las nuevas instituciones y controlar el crecimiento de la planta urbana $^{45}$. Los sucesivos conflictos armados fueron retrasando la propuesta de Reyes, que Lamas retomó en 1843. La tarea de confección del plano, que se entendía como una tarea policial, fue supervisada directamente por Lamas, quien elaboró "un folleto que conten[ía] todos los documentos relativos a la nomenclatura de las calles y numeración de las puertas" ${ }^{46}$. Desconocemos a quiénes estaba destinado ese folleto, pero podríamos pensar que, además de a la población en general, tenía como destinatarios a los funcionarios policiales. El nuevo mapa cumplió con dos funciones centrales: en primer lugar, tuvo relevancia en la planificación urbanística, ya que proyectaba no sólo lo edificado en Montevideo, sino que mostraba el amanzanamiento de la Nueva Ciudad; en segundo lugar, resultó clave para fijar las líneas defensivas en el contexto del sitio y contar con una descripción pormenorizada del territorio que se vigilaba, controlaba y defendía.

31 Con el nomenclátor y el plano de la ciudad, Lamas pretendía regular el proceso de creciente urbanización que se había tornado incontrolable. Podríamos pensar que este afán organizativo no era privativo del jefe político analizado, sino que varias autoridades del período se refirieron a las dificultades generadas por una ciudad en permanente expansión. Según el relevamiento de población de 1843, la Ciudad Vieja 
contaba con 101 edificios construidos, mientras que en la Ciudad Nueva había 519 edificaciones registradas ${ }^{47}$. La zona marcada entre la Ciudadela y el Ejido de la ciudad fue la que más creció en ese momento, en parte por construcciones realizadas sin permiso y regularización, que poco a poco fueron venciendo la prohibición colonial de construir sobre esas tierras. A eso se agrega que la guerra modificó en forma drástica la situación, ya que buena parte de la población procedente del medio rural fue reasentada en las áreas nuevas de la ciudad ${ }^{48}$. Esto llevó a que la policía se hiciera cargo de la vigilancia de nuevas zonas y caminos y provocó la destinación de un número mayor de oficiales y auxiliares a las nacientes jurisdicciones.

La tarea de Besnes e Irigoyen fue continuada por Pedro Pico, catedrático de matemáticas y dibujante de la Comisión Topográfica, a quien debemos el plano de la Vieja y Nueva ciudad, acompañado de una visión ampliada de toda la jurisdicción de Montevideo, su línea defensiva y la zona que estaba bajo control del ejército sitiador. Pico asumió el cargo de oficial delineador de la Comisión Topográfica en agosto de 1844, con intención de reforzar la tarea de confección y elaboración de planos de la ciudad ${ }^{49}$. En el plano que se encuentra abajo se puede observar el crecimiento de Montevideo y la ocupación de zonas cercanas a la línea defensiva.

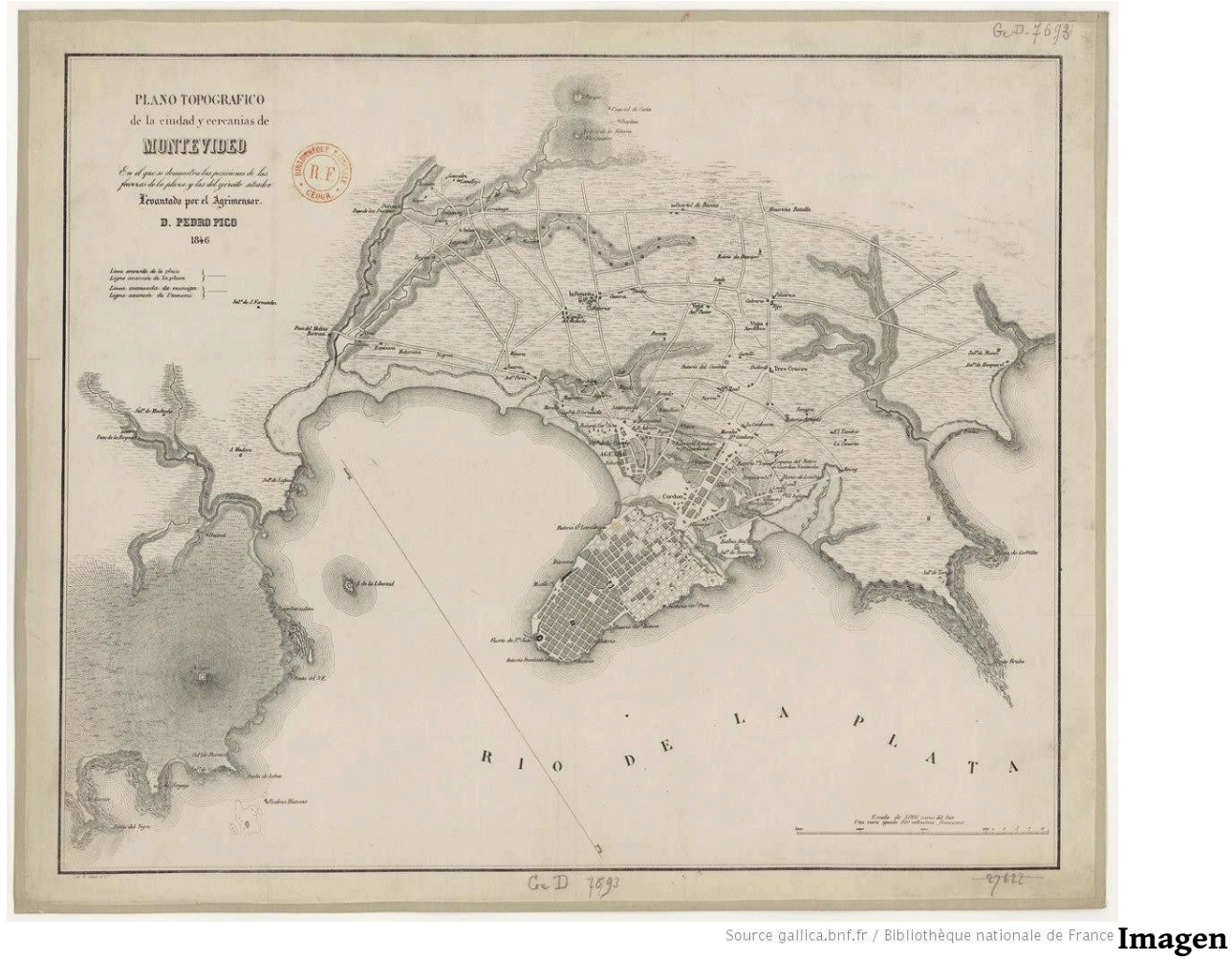

3. Plano de Montevideo de Pedro Pico, elaborado en 1846, publicado en Lettre a M. les Membres de L'Assamblée Nationale sur la question de la Plata par Charles Christofle Manufacturier Accompagnée des pieces suivantes Notice Geographique; plan de Montevideo Carte Geographique pour servir a L'Etude de la question du Río de la Plata Notice Chronologique, Historique et Politique, París, Imprimerie D’Eugène Duverger, 1849.

El nombramiento de nuevas calles, numeración de las puertas y confección de planos y mapas, estuvo acompañada por la labor estadística de relevamiento poblacional, de bienes materiales, edificaciones y comercios, también emprendida por Lamas. sistemático de la población anteceden al período bélico. El 14 de julio de 1837 una ley 
sobre estadística estableció que los curas párrocos debían remitir la información poblacional a los jefes de policía de cada departamento, resumiendo número de bautismos, matrimonios y defunciones. Los médicos también estaban obligados a pasar la cantidad de enfermos tratados y número de defunciones, con indicación de edad, sexo y enfermedad o causal de muerte del occiso. Con esa información

"la Junta de Higiene Pública formará cada cuatrimestre tres tablas, una de nacimientos y matrimonios de todo el territorio de la República referentes al trimestre trascurrido indicando la primera los sexos correspondientes; y dos de mortalidad de las cuales una espresará las edades y sexos de los fallecidos en dicho periodo y la otra las enfermedades ó accidentes a que hubiesen sucumbido" ${ }^{50}$.

A su vez, la realización de un censo de todo el territorio había sido aprobada por el gobierno el 27 de noviembre de 1841 y buscaba relevar sobre todo el número de inmigrantes ${ }^{51}$. Las vicisitudes de la guerra fueron retrasando la tarea, que se redujo a Montevideo en 1843.

La diferencia entre el período previo y la etapa en que Lamas fue jefe político radica en que la autoridad policial elaboró un proyecto de censo y que la iniciativa partió de la policía y no de otras reparticiones públicas. El llamado "Censo de 1843" fue llevado a cabo por la Policía de Montevideo, que relevó los principales datos de la ciudad. Esto permitió a las autoridades contar con un número útil, aunque relativo, para planificar la defensa.

La estadística fue interpretada por Lamas como un instrumento de centralización de la información, tal como da cuenta la introducción a sus Apuntes Estadísticos. Es en ese tipo de tareas rutinarias, minuciosas, de un esfuerzo muy grande en un contexto completamente adverso, que se puede apreciar la importancia conferida por la administración al relevamiento de información. El conocimiento de los habitantes de cada calle o casa, de las tareas a que se dedicaban, también debe ser analizado como parte del proceso de construcción estatal. Aparecen en el informe datos sobre adelantos materiales, incluido el plano topográfico, licencias expedidas para la edificación (con propietario y valor de tasación), distribución de la propiedad, proyección de nuevas poblaciones, buques, carruajes, establecimientos industriales, comerciales y mercantiles, consumo de bienes de primera necesidad, asistencia pública y a las obras de caridad, cárcel pública y biblioteca, nomenclátor, fiestas públicas, Instituto Histórico y Geográfico, instrucción pública, un apéndice con "análisis químico[s] de diversos productos naturales del territorio de la República Oriental del Uruguay", así como una descripción de plantas y minerales. En las notas, Lamas compara las cifras de Montevideo con las obtenidas en las principales ciudades europeas (en especial Londres y París) y algunas de la región.

38 Nomenclátor, planos y datos numéricos fueron pilares del esfuerzo administrativo de la tarea policial, de una racionalidad burocrática capaz de hacer de la ciudad un espacio de gestión. Los Apuntes Estadísticos, cuya introducción se publicó en París en 1851, rescataban información desde 1803 en adelante, por lo que también contribuían a dimensionar desde el punto de vista histórico las transformaciones ocurridas en el territorio oriental. De acuerdo con las notas dispersas de Lamas, su intención era comprender "los fenómenos fisiólogo-morales que presentan las diversas razas europeas y africanas trasplantadas a este suelo, sometidas a las influencias naturales de su localidad y a las particulares de su estado social" ${ }^{52}$. En esa introducción Lamas adelantaba una obra más extensa que finalmente no se concretó, pero daba cuenta de una preocupación que no se restringía sólo a las cifras de población. Los datos fueron 
utilizados por Lamas para sus obras, que lo consagraron como uno de los historiadores más destacados del siglo XIX ${ }^{53}$. Por ejemplo, todas las instituciones mencionadas (que van desde hospitales a bibliotecas públicas) fueron contextualizadas, e incluso hay un pequeño ensayo de historia de la industria en territorio oriental, que intentó rescatar los adelantos técnicos introducidos desde la década de 1830 .

En un análisis desde la demografía histórica, Raquel Pollero demostró que el llamado "Censo de 1843" o "Censo de Lamas", fue en realidad un relevamiento poblacional no estadístico, en tanto se realizó por etapas y no en un período de tiempo acotado. El trabajo documental realizado por Pollero permite afirmar que las listas corresponden a dos períodos de relevamientos de hogares, realizados el mismo año, una entre el 6 y 9 de febrero de 1843 -antes del inicio del sitio a la ciudad, que comenzó el 16 de ese mesy otro que se hizo durante el mes de septiembre. La historiadora evidenció esta situación siguiendo las órdenes enviadas por Lamas a sus subalterno ${ }^{54}$.

El relevamiento de 1843 fue encomendado a los tenientes alcaldes que debían recoger la información de la jurisdicción o manzana asignada. Las planillas -que se conservan en el Archivo General de la Nación ${ }^{55}$ - registraban sección de ciudad, manzana, calle, número de puerta, nombre, apellido, patria, edad, sexo, estado, profesión y condición de propietario o inquilino de la persona y familias que habitaban la finca. De los 31189 habitantes de Montevideo, 16603 eran hombres y 14437 mujeres, mientras 239 casos no se especificaron. De acuerdo con los datos relevados por Pollero y Graciana Sagaseta, el 52\% de la población de Montevideo habitaba en las secciones correspondientes a la Ciudad Vieja, el área de más antigua ocupación y mayor densidad poblacional.

\begin{tabular}{|l|l|}
\hline Secciones & Total \\
\hline 1 & 4990 \\
\hline 2 & 5995 \\
\hline 3 & 6434 \\
\hline 4 & 5043 \\
\hline 5 & 4804 \\
\hline Aldea & 569 \\
\hline Punta Brava & 531 \\
\hline Se ignora & 5040 \\
\hline Total & 33315 \\
\hline
\end{tabular}

41 Tabla 1. Individuos censados en 1843 (no toma en cuenta las distintas fechas, se establecen los números totales). Elaborado en base a Raquel Pollero, Graciana Sagaseta, "Caracterización sociodemográfica y análisis espacial de la población de Montevideo en 1843", p. 6. Disponible en: http://www.alapop.org/Congreso2018/PDF/0118a.pdf.

Las tareas "censales" se podrían complementar con los partes diarios y mensuales de los comisarios de sección, que contribuyeron a generar un gran mapa de información policial, que facilitaba el control del territorio. Los agentes de calle traducían en cifras y datos el territorio mediante un control permanente de lo que ocurría en sus jurisdicciones. Por supuesto que este señalamiento no establece que la labor policial 
podía cubrir todas las zonas del mundo urbano o que nos acercamos a una institución total, capaz de dominar todo lo que la compete. No pensamos en las concreciones, sino en las intenciones e iniciativas del jefe policial. A lo que se agrega que las tareas de vigilancia -y relevar información lo era- fueron cada vez más aceptadas.

\section{A modo de cierre: legados y continuidades}

En el trabajo intentamos analizar algunas de las propuestas impulsadas por Andrés Lamas, que fueron aplicadas durante el año y medio que duró su jefatura (aunque, como se señaló, algunos de los instrumentos descritos existían desde el período previo). En esa dirección es que podemos encontrar cierto grado de continuidad en los dos primeros años del sitio de Montevideo y lo que se llevó adelante en los años inmediatos y luego de finalizada la Guerra Grande.

La jefatura de Lamas fue un momento único porque el sitio de la ciudad obligó a llevar adelante una economía de guerra en un contexto adverso y de suma fragilidad para los políticos sitiados en la ciudad ${ }^{56}$. A su vez, se caracterizó por el desarrollo de instrumentos que permitieron y facilitaron el conocimiento sobre la ciudad con una clara intención o misión de tipo preventivo. De este modo, la eficacia policial pasaba más por aquellos desórdenes o delitos que evitaba que por su actuación inmediata. En la concepción de Lamas, eso se lograba a través de la información, del conocimiento sobre los habitantes, construcciones, casas, comercios o talleres, entre otros datos registrados en el relevamiento de 1843.

En el desarrollo de esos instrumentos policiales resultó importante contar con planos que facilitaran la tarea de conocer en detalle el territorio y que incluyeran, por ejemplo, la nueva nomenclatura de las calles (que mayoritariamente sobrevive hasta hoy) y los números de puerta manzana a manzana. Pensemos en una ciudad cuya población estaba conformada por un tercio de habitantes nacidos en territorio oriental y dos tercios fuera de las (débiles) fronteras políticas. ¿Cómo podría trabajar un oficial de policía no nacido en la ciudad? Un plano, un nomenclátor, eran mecanismos posibles para que conociera su área de trabajo. Esta función no fue privativa de la policía, ya que luego de la Guerra Grande se comenzaron a configurar otros saberes expertos que contribuyeron con la organización de la ciudad y, por ende, reprodujeron una forma de ver la sociedad. Desde la segunda mitad del siglo XIX, agrimensores, médicos o ingenieros también comenzaron a cumplir un papel central en el conocimiento del territorio.

Por su parte, el sistema de pasaportes y el aviso a la policía sobre el arribo o partida de la ciudad se instauró como una dinámica policial más, tarea que no se abandonó una vez finalizado el conflicto. Una situación análoga se podría señalar con las papeletas laborales, que luego de la guerra fueron replicadas en reglamentaciones que pretendieron abarcar a todo el territorio. En un caso se buscaba controlar a posibles enemigos, en otro a la población fluctuante (que incluía a trabajadores), los cuales eran confinados a determinados espacios laborales, a través de una delimitación policial que establecía zonas y horarios de trabajo.

47 Otro cambio posterior que se vincula con el período de Lamas fue el intento por comenzar a reglamentar en forma cada vez más certera el trabajo policial. El reglamento vigente era el de 1827, al que las autoridades consideraban insuficiente para enfrentar las transformaciones que el territorio nacional y Montevideo habían 
vivido durante la década de 1830 y el transcurso del sitio. Lamas fue un fuerte defensor de las tareas comisariales e insistió en el carácter civil de la policía, con intención de separar a la institución de los movimientos militares (regulares y milicianos) que se registraban en Montevideo. Sin embargo, en este período no hubo propuestas específicas de reforma de la administración (comprensible tal vez si tenemos en cuenta la excepcionalidad de la situación).

El 18 de junio de 1848 se creó el cargo de oficial mayor del Departamento de Policía de Montevideo, reemplazo inmediato del jefe policial titular y responsable de los edictos y disposiciones, así como órdenes del día enviadas por la principal autoridad ${ }^{57}$. En 1846 y nuevamente en 1848 se presentó un proyecto de reglamento interno sustitutivo del vigente, que finalmente no fue aprobado. La iniciativa, del oficial primero Francisco Manuel Lebrou, tiene relación con Lamas: el autor del proyecto, según declaró, era funcionario policial desde 1836 (aunque lo encontramos mencionado desde 1839). En marzo de 1853 fue designado jefe político de Montevideo ${ }^{58}$. El segundo motivo se debe a que varias de las iniciativas de la propuesta de Lebrou ya habían sido defendidas por Lamas en sus escritos o notas cursadas al Ministerio de Gobierno (existencia de un oficial primero, comisarios, jurisdicciones específicas por sección). En los proyectos presentados al gobierno en 1846 y 1848, Lebrou sostuvo que el reglamento buscaba "establecer una base fundamental que demarque las atribuciones en el ejercicio de las funciones de todo empleado del Departamento de Policía". Para ello definió a cada uno de los empleados del rubro y sus consiguientes atribuciones, reafirmó la división de la ciudad en jurisdicciones por comisaría, e insistió en el respeto irrestricto de los derechos individuales, para lo cual brindó disposiciones relativas a las detenciones, traslados y apresamiento de las personas. El proyecto de reglamento dedicó una parte al problema de la vagancia y la reglamentación de la actividad laboral, que buscaban, "[p]roteger en todo lo posible la seguridad individual y el derecho de propiedad" ${ }^{59}$. En esa dirección podríamos establecer un paralelismo con la actuación de Lamas, aunque también con la de otros jefes policiales del período, en la medida que encontramos una fuerte insistencia en la división seccional y la impronta comisarial.

El nacimiento de un nuevo sentido policial complementó las funciones que se desarrollaban en la etapa prebélica, por lo que más que provocar la aparición de una nueva policía, podríamos pensar en nuevas funciones que complementaron las existentes, que buscaban el mantenimiento del orden urbano. Los cambios no fueron lineales -nunca pueden ser analizados desde esa óptica en la historia del Estado-, pero la administración Lamas permitió sedimentar las bases de un tipo de labor policial que caracterizó a la segunda mitad del siglo XIX. Por eso podemos considerar al período de Lamas como una etapa novedosa, en la que comenzó a visualizarse una nueva práctica policial, a través de reglamentos, formas de funcionamiento y el equipamiento político del territorio. Todo ello acompañado de un creciente proceso de centralización de la autoridad política, no necesariamente efectiva, pero sí considerada necesaria.

\section{Fuentes}

\section{Fuentes inéditas}

AGN, Archivo General de la Nación, Montevideo, Uruguay 
Archivo General Administrativo, Ministerio de Gobierno, libro 1401: Registro Nacional de Leyes acuerdos y decretos.

Documentos de la Administración Central, Fondo Ex Ministerio de Gobierno y Ministerio del Interior, cajas 943, 944, 968.

Ex-Archivo y Museo Histórico Nacional, fondo Dr. Andrés Lamas, cajas 119, 160.

Historia de la Administración, Libros, Ministerio de Gobierno, Libro 1401, Acuerdos y decretos del Ministerio de Gobierno, 1830 a 1852.

La Gaceta Mercantil, Buenos Aires, 12 de febrero de 1844.

\section{Fuentes publicadas}

Armand Ugón, E.; Cerdeiras Alonso, J. C; Arcos Ferrand, L.; y Goldaracena, C., Compilación de leyes y decretos 1825-1930, s.d., Montevideo, 1930, tomo II.

Arredondo, Horacio, “Los 'Apuntes estadísticos' del Dr. Andrés Lamas”, Revista del Instituto Histórico y Geográfico del Uruguay, Montevideo, Vol. VI, n¹, 1928, pp. 25-195.

Blanco Acevedo, Pablo, Escritos selectos del Doctor Andrés Lamas, Instituto Histórico y Geográfico del Uruguay, Montevideo, 1922.

Constitución de la República Oriental del Uruguay, promulgada el 28 de junio de 1830, Disponible en: https://parlamento.gub.uy/documentosyleyes/documentos/10/HTML? width $=800 \&$ height $=600 \&$ hl $=$ en_US1\&iframe $=$ true\&rel $=0$. [Fecha de consulta: 23 de julio de 2020]

Iconografía de Montevideo, Concejo Departamental de Montevideo, Montevideo, 1955. 205 p.

Lamas, Andrés, Escritos selectos del Dr. D. Andrés Lamas, Tipografía Moderna, 1922, Montevideo, Vol. I.

Nomenclátor de las calles y plazas de la ciudad y principales caminos del departamento, Junta Económico-Administrativa, Montevideo, 1902.122 p.

María, Isidoro de, Anales de la Defensa de Montevideo. 1842-1851, Imprenta El Ferro-Carril, Montevideo, 1883, tomo I.

4 Villalba, Antonio, Manual de policía, Establecimiento Tipográfico a vapor de La Idea, Montevideo, 1874.

Wright, Francisco Agustín, Montevideo. Apuntes históricos de la defensa de la república, Imprenta del Nacional, Montevideo, 1846. 448 p.

\section{BIBLIOGRAFÍA}

Acevedo, Eduardo, Anales históricos del Uruguay, Barreiro y Ramos, Montevideo, 1933, tomos II y V. 
Aliata, Fernando, La ciudad regular. Arquitectura, programas e instituciones en el Buenos Aires posrevolucionario, 1821-1835, Universidad Nacional de Quilmes/Prometeo Libros, Quilmes, 2006. 303 p.

Alpini, Alfredo, Montevideo: ciudad, policía y orden urbano (1829-1865), s.d., Montevideo, 2017. 301 p.

Alpini, Alfredo, La policía y la ciudad de Montevideo: orden urbano y control social en la construcción del Estado moderno en Uruguay. 1829-1916, Instituto de Investigaciones Históricas Dr. Ramón Leoni Pinto, Facultad de Filosofía y Letras, Universidad Nacional de Tucumán, San Miguel de Tucumán, 2018. 330 p.

Barriera, Darío “Conjura de mancebos. Justicia, equipamiento político del territorio e identidades. Santa Fe del Río de la Plata, 1580”, en Barriera, Darío (comp.), Justicias y fronteras. Estudios sobre historia de la justicia en el Río de la Plata. Siglos XVI-XIX, Editum, Murcia, 2009, pp. $11-50$.

Barriera, Darío, “El alcalde de barrio, de justicia a policía (Río de la Plata, 1770-1830)”, Nuevo Mundo Mundos Nuevos, en línea, 2017. Disponible en: http://nuevomundo.revues.org/70602. [Fecha de consulta: 23 de julio de 2020]

Beretta, Ernesto, Imágenes para todos. La producción litográfica, la difusión de la estampa y sus vertientes temáticas en Montevideo durante el siglo XIX. Primera etapa, de la construcción del Estado Oriental al fin de la Guerra Grande (1829-1851), Comisión Sectorial de Investigaciones Científicas de la Universidad de la República, Montevideo, 2015. 223 p.

Bonaudo Marta, “Aires gaditanos en el mundo rioplatense. La experiencia de los jefes políticos y el juicio por jurados en tierras santafesinas (segunda mitad del siglo XIX)", Revista de Indias, Sevilla, Vol. LXVIII, n²42, 2008, pp. 255-280.

Bresciano, Ruben, La Junta Económico-administrativa de Montevideo, Intendencia Municipal de Montevideo, Montevideo, 1979. $61 \mathrm{p}$.

Caetano, Gerardo (dir.) y Frega, Ana (coord.), Historia contemporánea del Uruguay. Tomo I:

Revolución, independencia y construcción del Estado, 1808-1880, Editorial Planeta/Fundación MAPFRE, Montevideo, 2016. 294 p.

Carmona, Liliana, Ciudad Vieja de Montevideo, 1829-1991. Transformaciones y propuestas urbanas, Fundación de Cultura Universitaria, Montevideo, 1993. 174 p.

Duffau, Nicolás, "Esta patria es el orden": el concepto de orden como proyecto político en territorio oriental (1820-1880)", en Chaparro, Juan (ed.), Independencia y nuevo orden: la América hispano-lusitana en el siglo XIX, Instituto Colombiano de Antropología e Historia, Bogotá, 2020, pp. 253-290.

Duffau, Nicolás, “La Policía en la Provincia Oriental (1826-1838). Una construcción institucional entre el Antiguo Régimen y el orden republicano”, Anuario IEHS, Tandil, Vol. 33, n¹, 2018, pp. 85-105.

Duffau, Nicolás y Etchechury, Mario, "Redes de espionaje y conspiraciones durante el inicio del Sitio Grande. Montevideo, 1843", Anuario Colombiano de Historia Social y de la Cultura, Bogotá, Vol. $46, \mathrm{n}^{\circ} 2$, jul.-dic. 2019, pp. 237-259.

Etchechury, Mario, “'Chinas, guayaquises y jente que no es de armas'. Algunas consideraciones sobre el impacto social de la guerra en Montevideo y su hinterland rural (1842-1845)", Prohistoria, Rosario, n²8, 2017, pp. 129-147. 
Falcón, Romana, El jefe político. Un dominio negociado en el mundo rural del Estado de México, 1856-1911, El Colegio de México/El Colegio de Michoacán/Centro de Investigaciones y Estudios Superiores en Antropología Social, México, 2015. 744 p.

Foucault, Michel, Seguridad, territorio, población, Fondo de Cultura Económica, Buenos Aires, 2006. $484 \mathrm{p}$.

Furlong. Guillermo, Bibliografía de Andrés Lamas, Academia Nacional de la Historia, Buenos Aires, 1944. $366 \mathrm{p}$.

Galeano, Diego, “Genealogía del comisario: policía y orden urbano en Buenos Aires”, Iberoamericana, Berlín, n64, 2017, pp. 13-33.

Godicheau, François, "Orígenes del concepto de orden público en España. Su nacimiento en un marco jurisdiccional”, Ariadna histórica. Lenguajes, conceptos, metáforas, San Sebastián, $n^{\circ} 2,2013$, pp. 107-130.

González, Ariosto, El manifiesto de Lamas en 1855, El Siglo Ilustrado, Montevideo, 1937. 146 p.

L'Heuillet, Helene, Baja política, alta policía. Un enfoque histórico y político de la policía, Prometeo Libros, Buenos Aires, 2010. 366 p.

Lanteri, Ana Laura y Piazzi, Carolina, "La administración pública en la Argentina en perspectiva histórica. Propuestas sobre el quehacer administrativo y las funciones judiciales y legislativas en torno a las décadas de 1850 y 1860", Revista de Historia Americana y Argentina, Mendoza, Vol. 54, no1, 2019, pp. 241-276.

Montero Bustamante, Raúl, Políticos y románticos, Centro Editor de América Latina, Montevideo, $1968.96 \mathrm{p}$.

Pérez Montero, Carlos, La calle 18 de Julio (1719-1875) Antecedentes para la historia de la ciudad nueva, El Siglo Ilustrado, Montevideo, 1942. 368 p.

Pollero, Raquel y Sagaceta, Graciana, “Una fotografía 'movida' de Montevideo a mediados del siglo XIX. Conversaciones entre la demografía histórica y el análisis espacial”, Población y Sociedad, Vol. 26, n², 2019, pp. 64-86.

Pollero, Raquel y Sagaseta, Graciana, "Caracterización sociodemográfica y análisis espacial de la población de Montevideo en 1843”, en VIII Congreso de la Asociación Latinoamericana de Población, Puebla, México, 23 a 26 de octubre de 2018. Disponible en: http://www.alapop.org/ Congreso2018/PDF/0118a.pdf. [Fecha de consulta: 23 de julio de 2020]

Pulido Esteva, Diego, "Policía: del buen gobierno a la seguridad, 1750-1850", Historia Mexicana, México, Vol. LX, n³, enero-marzo 2011, pp. 1595-1642.

Sansón, Tomás, Despertar en Petrópolis. Andrés Lamas y la influencia de Brasil en la historia de los Estados de la Cuenca del Plata en el siglo XIX, Sicut Serpentes, Montevideo, 2015. 205 p.

Silva Cazet, Elisa, "En torno a la nomenclatura de Montevideo y a la formación de una conciencia histórica”, Revista de la Biblioteca Nacional, Montevideo, n²4, 1986, pp. 79-90.

Terra, Mercedes, Montevideo durante la Guerra Grande, Byblos, Montevideo, 2007. 132 p.

Thul, Florencia "Mercado de trabajo y movilización militar en Montevideo durante la Guerra Grande (1838-1851)", Claves. Revista de Historia, Montevideo, Vol. 5, n8, enero-junio 2019, pp. 7-34. Thul, Florencia, Coerción y relaciones de trabajo en el Montevideo independencia. 1829-1842, Tesis para optar el grado de Magíster en Historia Rioplatense, Universidad de la República, Montevideo, 2014. 178 p. 
Vélez Rendón, Juan Carlos, “'Desconductadas costumbres’ y ‘semillas de la discordia'. Prácticas de oposición y resistencia a los jefes políticos en el nordeste de Antioquia (1821-1843)”, Historia Crítica, Bogotá, n47, 2012, pp. 45-70.

Victoria Rodríguez, José, Evolución histórica de la policía uruguaya, Byblos, Montevideo, 2008, tomo III.

Wasserman, Fabio, "Relato histórico e identidad nacional en la nomenclatura de Montevideo de 1843”, Memoria Social, Bogotá, n¹4, enero-junio 2010, pp. 51-65.

Yangilevich, Melina, "Prefecturas, comisarías de campaña y construcción estatal en la Provincia de Buenos Aires (Argentina) a mediados del siglo XIX”, Secuencia, México, n¹02, pp. 70-99.

\section{NOTAS}

1. Algunas biografías sobre la figura de Lamas, que rescatan sobre todo su dimensión intelectual y política en González, Ariosto, El manifiesto de Lamas en 1855, El Siglo Ilustrado, Montevideo, 1937; Montero Bustamante, Raúl, Políticos y románticos, Centro Editor de América Latina, Montevideo, 1968; Sansón, Tomás Despertar en Petrópolis. Andrés Lamas y la influencia de Brasil en la historia de los Estados de la Cuenca del Plata en el siglo XIX, Sicut Serpentes, Montevideo, 2015.

2. Sobre los escritos de Lamas véase Blanco Acevedo, Pablo, Escritos selectos del Doctor Andrés Lamas, Instituto Histórico y Geográfico del Uruguay, Montevideo, 1922; Furlong, Guillermo, Bibliografía de Andrés Lamas, Academia Nacional de la Historia, Buenos Aires, 1944.

3. Lamas, Andrés, Escritos selectos del Dr. D. Andrés Lamas, Tipografía Moderna, Montevideo, 1922, Vol. I, pp. 47-78.

4. Podríamos vincular los instrumentos policiales con lo que Darío Barriera llamó "equipamiento político del territorio". Véase Barriera, Darío "Conjura de mancebos. Justicia, equipamiento político del territorio e identidades. Santa Fe del Río de la Plata, 1580", en Barriera, Darío (comp.), Justicias y fronteras. Estudios sobre historia de la justicia en el Río de la Plata. Siglos XVI-XIX, Editum, Murcia, 2009, pp. 11-50.

5. Archivo General de la Nación (AGN), Ex-Archivo y Museo Histórico Nacional (ex MHN), Dr. Andrés Lamas, caja 119, carpeta 6 [20 de marzo de 1843]; caja 160 [1ํ de setiembre de 1843]. Si bien circulaban distintas nociones sobre la "ciencia" de policía, Lamas no remite a ningún texto específico. Fernando Aliata ha sostenido que la idea de la administración urbana como parte de una ciencia aplicaba disciplinas como la medicina, la química, la arquitectura o la estadística económica, que se entendía favorecían una intervención directa para evitar el desorden y la expansión descontrolada de la ciudad. Aliata, Fernando, La ciudad regular. Arquitectura, programas e instituciones en el Buenos Aires posrevolucionario, 1821-1835, Universidad Nacional de Quilmes/ Prometeo Libros, Quilmes, 2006, pp. 60-61.

6. En los últimos años la historiografía latinoamericana comenzó a prestar atención a las jefaturas políticas y policiales como objeto de investigación. Algunos trabajos se detienen en analizar el rol de la jefatura como institución y otros avanzan en el papel de los jefes como mediadores entre las altas esferas gubernamentales y las demandas de los sectores populares. Véase Falcón, Romana, El jefe político. Un dominio negociado en el mundo rural del Estado de México, 1856-1911, El Colegio de México/El Colegio de Michoacán/Centro de Investigaciones y Estudios Superiores en Antropología Social, México, 2015; Bonaudo, Marta, "Aires gaditanos en el mundo rioplatense. La experiencia de los jefes políticos y el juicio por jurados en tierras santafesinas (segunda mitad del siglo XIX)”, Revista de Indias, Sevilla, Vol. LXVIII, n²42, 2008, pp. 255-280; Vélez Rendón, Juan Carlos, “'Desconductadas costumbres' y ‘semillas de la discordia'. Prácticas de oposición y resistencia a los jefes políticos en el nordeste de Antioquia (1821-1843)”, Historia 
Crítica, Bogotá, n47, 2012, pp. 45-70; Yangilevich, Melina, "Prefecturas, comisarías de campaña y construcción estatal en la Provincia de Buenos Aires (Argentina) a mediados del siglo XIX", Secuencia, México, n¹02, pp. 70-99; Lanteri, Ana Laura y Piazzi, Carolina, "La administración pública en la Argentina en perspectiva histórica. Propuestas sobre el quehacer administrativo y las funciones judiciales y legislativas en torno a las décadas de 1850 y 1860 ", Revista de Historia Americana y Argentina, Mendoza, Vol. 54, ํㅜ1, 2019, pp. 241-276.

7. L'Heuillet, Helene, Baja política, alta policía. Un enfoque histórico y político de la policía, Prometeo Libros, Buenos Aires, 2010, en especial pp. 41-59.

8. Foucault, Michel, Seguridad, territorio, población, Fondo de Cultura Económica, Buenos Aires, 2006, pp. 371-376.

9. Godicheau, François, "Orígenes del concepto de orden público en España. Su nacimiento en un marco jurisdiccional”, Ariadna histórica. Lenguajes, conceptos, metáforas, San Sebastián, n², 2013, pp. 107-130.

10. Sobre la idea del orden, Duffau, Nicolás, “'Esta patria es el orden': el concepto de orden como proyecto político en territorio oriental (1820-1880)", en Chaparro, Juan Carlos (ed.), Independencia y nuevo orden: la América hispano-lusitana en el siglo XIX, Instituto Colombiano de Antropología e Historia, Bogotá, 2020, pp. 253-290.

11. Las jefaturas políticas y de policía eran una institución intermedia dependiente del Ministerio de Gobierno, una de las tres carteras que (junto a Hacienda y Guerra y Marina) formaban el Poder Ejecutivo. Duffau, Nicolás, "La Policía en la Provincia Oriental (1826-1838). Una construcción institucional entre el Antiguo Régimen y el orden repúblicano”, Anuario IEHS, Tandil, Vol. 33, n¹, 2018, pp. 85-105.

12. Caetano, Gerardo (dir.) y Frega, Ana (coord.), Historia contemporánea del Uruguay. Tomo I: Revolución, independencia y construcción del Estado, 1808-1880, Editorial Planeta/Fundación MAPFRE, Montevideo, 2016, pp. 71-72.

13. Constitución de la República Oriental del Uruguay, promulgada el 28 de junio de 1830, artículos 118 a 121.

14. Bresciano, Ruben, La Junta Económico-administrativa de Montevideo, Intendencia Municipal de Montevideo, Montevideo, 1979, p. 22; Alpini, Alfredo, Montevideo: ciudad, policía y orden urbano (1829-1865), s.d., Montevideo, 2017, pp. 85-91.

15. AGN, Documentos de la Administración Central (DAC), Fondo Ex Ministerio de Gobierno y Ministerio del Interior (FEMGMI), caja 944, carpeta 5, documento 174 [Montevideo, 4 de marzo de 1843]. Lamentablemente, desconocemos cuál fue la respuesta de la autoridad superior. No obstante, podríamos interpretar los respaldos públicos hacia la actuación de Lamas como una señal de apoyo.

16. Etchechury, Mario, “'Chinas, guayaquises y jente que no es de armas'. Algunas consideraciones sobre el impacto social de la guerra en Montevideo y su hinterland rural (1842-1845)", Prohistoria, Rosario, n²8, 2017, pp. 129-147.

17. Arredondo, Horacio, “Los ‘Apuntes Estadísticos' del Dr. Andrés Lamas”, Revista del Instituto Histórico y Geográfico del Uruguay, Montevideo, Vol. VI, n¹, 1928, pp. 25-195.

18. Acevedo, Eduardo, Anales históricos del Uruguay, Barreiro y Ramos, Montevideo, 1933, tomo V, p. 191.

19. Véase Duffau, Nicolás y Etchechury, Mario, "Redes de espionaje y conspiraciones durante el inicio del Sitio Grande. Montevideo, 1843", Anuario Colombiano de Historia Social y de la Cultura, Bogotá, Vol. 46, n², enero-junio 2019, pp. 237-259.

20. Decreto tomado de Wright, Francisco Agustín, Montevideo. Apuntes históricos de la defensa de la república, Imprenta del Nacional, Montevideo, 1846, p. 145.

21. Decreto tomado de Wright, F., Montevideo, Op. Cit., p. 145. 
22. Pollero, Raquel y Sagaceta, Graciana, “Una fotografía 'movida' de Montevideo a mediados del siglo XIX. Conversaciones entre la demografía histórica y el análisis espacial”, Población y Sociedad, Buenos Aires, Vol. 26, n², año 2019, p. 79.

23. AGN, ex Ex-MHN, Dr. Andrés Lamas, c. 160 [1ํ de setiembre de 1843].

24. AGN, ex Ex-MHN, Dr. Andrés Lamas, c. 160 [1ํ de setiembre de 1843].

25. Al respecto véase Thul, Florencia "Mercado de trabajo y movilización militar en Montevideo durante la Guerra Grande (1838-1851)", Claves. Revista de Historia, Montevideo, Vol. 5, nº, enerojunio 2019, pp. 7-34.

26. Terra, Mercedes, Montevideo durante la Guerra Grande, Byblos, Montevideo, 2007, p. 53.

27. Al respecto véase Thul, Florencia, Coerción y relaciones de trabajo en el Montevideo independencia. 1829-1842, Tesis para optar el grado de Magíster en Historia Rioplatense, Universidad de la República, Montevideo, 2014.

28. AGN, DAC, FEMGMI, c. 944, c. 5, f. 203 [Montevideo, 17 de marzo de 1843], Andrés Lamas al ministro de Gobierno Santiago Vázquez.

29. La Gaceta Mercantil, Buenos Aires, 12 de febrero de 1844, pp. 2-3.

30. AGN, ex MHN, Archivo del Doctor Andrés Lamas, c. 119, c. 7.

31. AGN, DAC, FEMGMI, c. 944, c. 6, f. 472. En febrero de 1844 unas seis mil personas dependían del sustento público para alimentarse a diario, cifra impactante para una ciudad que contaba con poco más de treinta y tres mil habitantes. Cifras tomadas de Etchechury, M., "“Chinas, guayaquises", Op. Cit., p. 143.

32. AGN, DAC, FEMGMI, c. 944, c. 7, f. 501.

33. AGN, ex MHN, Archivo del Doctor Andrés Lamas, c. 119, c. 6 [20 de marzo de 1843].

34. María, Isidoro de, Anales de la defensa de Montevideo, 1842-1851, Imprenta El Ferro-Carril, Montevideo, 1883, tomo I, pp. 138-139.

35. Véase "División territorial", en Armand Ugón, E.; Cerdeiras Alonso, J. C; Arcos Ferrand, L. y Goldaracena, C., Compilación de leyes y decretos 1825-1930, s.d., Montevideo, 1930, tomo II, pp. 64-65.

36. Alpini, Alfredo, La policía y la ciudad de Montevideo: orden urbano y control social en la construcción del Estado moderno en Uruguay. 1829-1916, Instituto de Investigaciones Históricas Dr. Ramón Leoni Pinto, Facultad de Filosofía y Letras, Universidad Nacional de Tucumán, San Miguel de Tucumán, 2018, p. 58.

37. Véase Galeano, Diego, “Genealogía del comisario: policía y orden urbano en Buenos Aires”, en Iberoamericana, Berlín, n64, 2017, pp. 13-33.

38. El plan de Lamas, junto a otros del siglo XIX, fue recopilado en Nomenclátor de las calles y plazas de la ciudad y principales caminos del departamento, Junta Económico-Administrativa, Montevideo, 1902, pp. 22-23.

39. Véase, por ejemplo, la propuesta de 1837 en AGN, Historia de la Administración (HA), Libros, Ministerio de Gobierno (MG), Libro 1401, Acuerdos y decretos del Ministerio de Gobierno, 1830 a 1852, f. 130: 31 de agosto de 1837, se crea la primera "Comisión para la nueva denominación de calles".

40. Véase Silva Cazet, Elisa, "En torno a la nomenclatura de Montevideo y a la formación de una conciencia histórica", Revista de la Biblioteca Nacional, Montevideo, n²4, 1986, pp. 79-90; Wasserman, Fabio, "Relato histórico e identidad nacional en la nomenclatura de Montevideo de 1843”, Memoria Social, Bogotá, n¹4, enero-junio 2010, pp. 51-65.

41. AGN, DAC, FEMGMI, c. 943, c. 3A, f. 295 [Montevideo, 21 y 22 de mayo de 1843].

42. En un proceso similar al que ocurrió en otras regiones: Barriera, Darío, "El alcalde de barrio, de justicia a policía (Río de la Plata, 1770-1830)", Nuevo Mundo Mundos Nuevos, en línea, 2017. Disponible en: http://nuevomundo.revues.org/70602; Pulido Esteva, Diego, "Policía: del buen gobierno a la seguridad, 1750-1850”, Historia Mexicana, México, Vol. LX, n³, enero-marzo 2011, pp. 1595-1642; Galeano, D., “Genealogía del comisario”, Op. Cit. 
43. Sobre los antecedentes de los planos topográficos de la ciudad véase: Pérez Montero, Carlos, La calle 18 de Julio (1719-1875), El Siglo Ilustrado, Montevideo, 1942; Iconografía de Montevideo, Concejo Departamental de Montevideo, Montevideo, 1955, pp. 109, 110; Beretta, Ernesto, Imágenes para todos. La producción litográfica, la difusión de la estampa y sus vertientes temáticas en Montevideo durante el siglo XIX. Primera etapa, de la construcción del Estado Oriental al fin de la Guerra Grande (1829-1851), Comisión Sectorial de Investigaciones Científicas de la Universidad de la República, Montevideo, 2015, pp. 175-181. Para todo el territorio rioplatense en la inmediata posrevolución Aliata, F., La ciudad regular, Op. Cit., pp. 62-72.

44. Carmona, Liliana, Ciudad Vieja de Montevideo. 1829-1991. Transformaciones y propuestas urbanas, Fundación de Cultura Universitaria, Montevideo, 1993, pp. 7-45.

45. Aliata, F., La ciudad regular, Op. Cit., pp. 55-62.

46. AGN, HA, MG, Libro 1401, Acuerdos y decretos del Ministerio de Gobierno, 1830 a 1852, fs. 188-189.

47. El historiador Eduardo Acevedo ha señalado que era frecuente que una licencia de construcción escondiera varias casas, ya que sus propietarios se unían para abonar el impuesto en una única ocasión. Por lo que podríamos pensar que el número de construcciones fue mayor al que figura en la documentación. Acevedo, Eduardo, Anales históricos del Uruguay, Barreiro y Ramos, Montevideo, 1933, tomo II, p. 32.

48. Pérez Montero, C., La Calle 18, Op., Cit., pp. 62-73.

49. AGN, HA, MG, Libro 1401, Acuerdos y decretos del Ministerio de Gobierno, 1830 a 1852, f. 193. 50. Tomado de Villalba, Antonio, Manual de policía, Establecimiento Tipográfico a vapor de La Idea, Montevideo, 1874, pp. 45-46.

51. AGN, Archivo General Administrativo (AGA), Ministerio de Gobierno, libro 1401: Registro Nacional de Leyes acuerdos y decretos. Decreto del Ministerio de Gobierno, Montevideo, noviembre 27 de 1841.

52. Arredondo, H., "Los “Apuntes estadísticos”, Op. Cit., p. 40.

53. Véase Sansón, T., Despertar en Petrópolis, Op. Cit.

54. Pollero, R. y Sagaceta, G., "Una fotografía 'movida”, Op. Cit.

55. Padrón de 1843, en AGN, DAC, FEMGMI, c. 943, c. 6.

56. En los dos primeros años del Sitio abundaron las acciones bélicas, las deserciones y los intentos por tomar la ciudad. Con el paso de los años, la presencia de los ejércitos a un lado y otro de la línea defensiva se normalizó, aunque, como fue señalado, la ciudad permaneció asediada por tierra y en algunos momentos por mar, hasta octubre de 1851.

57. AGN, HA, MG, Libro 1401, Acuerdos y decretos del Ministerio de Gobierno, 1830 a 1852, f. 239.

58. Victoria Rodríguez, José, Evolución histórica de la policía uruguaya, Byblos, Montevideo, 2008, tomo III, p. 443.

59. AGN, DAC, FEMGMI, c. 968 , c. 4 A.

\section{RESÚMENES}

El artículo estudia el paso de Andrés Lamas por la jefatura política y de policía de Montevideo entre 1843 y 1844 y analiza algunas de las tareas propuestas o emprendidas durante su administración, para ver las reformas policiales promovidas, las características que adoptó el control interior de la ciudad sitiada durante la Guerra Grande, y el desarrollo de algunos 
instrumentos "modernos" que buscaron facilitar la actuación policial. El trabajo intenta insertar la biografía de Lamas en el análisis de trayectorias policiales y de este modo atender su importancia como funcionario administrativo, y no sólo como uno de los intelectuales más relevantes del siglo XIX en el Río de la Plata, principal aspecto destacado por la mayor parte de sus biógrafos.

The article studies the Andrés Lamas police administration in Montevideo between 1843 and 1844 and analyzes some of the tasks proposed or undertaken, and the police reforms promoted, the characteristics adopted by the internal control of the city besieged during the Great War, and the development of some "modern" instruments that sought to facilitate police work. The paper attempts to insert the biography of Lamas in the analysis of police trajectories and thus attend to its importance as an administrative official, and not only as one of the most prominent intellectuals of the XIX century in the Río de la Plata, the main aspect highlighted by the most of his biographers.

L'article étudie le passage d'Andrés Lamas dans le quartier général politique et policier de Montevideo entre 1843 et 1844 et analyse certaines des tâches proposées ou entreprises pendant son administration, pour voir les réformes policières promues, les caractéristiques adoptées par le contrôle intérieur de la ville assiégée pendant la Grande Guerre, et le développement de certains instruments "modernes" qui ont cherché à faciliter l'action de la police. Le texte tente d'insérer la biographie de Lamas dans l'analyse des trajectoires policières et d'aborder ainsi son importance en tant qu'agent administratif, et pas seulement en tant qu'un des intellectuels les plus importants du XIXe siècle dans le Rio de la Plata, aspect principal mis en évidence par la plupart de ses biographes.

\section{ÍNDICE}

Mots-clés: Montevideo, Guerra Grande, Police, Andrés Lamas, XIXe siècle

Keywords: Montevideo, Guerra Grande, Police, Andrés Lamas, XIX Century

Palabras claves: Montevideo, Guerra Grande, policía, Andrés Lamas, siglo XIX

\section{AUTOR}

\section{NICOLÁS DUFFAU}

Doctor en Historia, Facultad de Filosofía y Letras Universidad de Buenos Aires. Facultad de Humanidades y Ciencias de la Educación, Universidad de la República, Uruguay/ Sistema Nacional de Investigadores-Agencia Nacional de Investigación e Innovación.Profesor Adjunto del Instituto de Historia e investigador del programa "Claves del siglo XIX en el Río de la Plata". Director del programa de doctorado. nduffau[at]fhuce.edu.uy 